\title{
The radical and requisite openness of viable systems - implications for healthcare strategy and practice
}

\author{
Felice Borghmans ${ }^{1}$ \\ ${ }^{1}$ Monash University
}

April 4, 2021

\begin{abstract}
This paper begs an ontological question about the nature of health and challenges some underpinning assumptions in western healthcare. In its analysis, the structure of health, in its various statuses, is framed as a complex adaptive system made up of dynamically interacting subsystems that include the physiological, psychological, spiritual, social, cultural, and more, realms. Furthermore, openness in complex systems such as health, is necessary for the exchange of energy, information, and resources. Yet, within healthcare much effort is invested in constraining systems' behaviours, whether they be systems of knowledge, states of health, models of care, and more. This paper draws on the complexity sciences and Levinasian philosophy to explicate the essential role of system openness in individual and population health, and the viability of healthcare systems. It highlights holism to be 'not whole-ism', and system openness to be, not just a reality, but a critical feature of viability. Hence requisite openness is advocated as essential to efficacious and ethical healthcare practice and strategy, and vital for good quality health.
\end{abstract}

\section{Hosted file}

THERAD 1.DOC available at https://authorea.com/users/405715/articles/516592-the-radical-andrequisite-openness-of-viable-systems-implications-for-healthcare-strategy-and-practice 